\title{
ОЦЕНКА ПОТЕНЦИАЛЬНОЙ ГИДРОМЕТЕОРОЛОГИЧЕСКОЙ УСТОЙЧИВОСТИ ЛАНДШАФТОВ КРЫМА
}

\author{
В.О.Жук \\ Таврическая академия (структьурное подразделение) «Крымский федеральный университет \\ им. В. И. Вернадского», Россия \\ Поступила в редакияию 14 ноября 2018 г.
}

\begin{abstract}
Aннотация: В статье анализируется влияния опасных гидрометеорологических, влияющих на устойчивость ландшафтов в Крыму. Выявлены наиболее устойчивые ландшафтные зоны на исследуемой территории. Устойчивость ландшафтов Крыма к опасным метеоявлениям может послужить основой для агрономии и сельского хозяйства, ландшафтного планирования, оценки его экологического потенциала и допустимого антропогенного освоения территории.
\end{abstract}

Ключевые слова: опасные гидрометеорологические явления, ландшафт, Крымский полуостров.

\section{Assessment of the potential hydrometeorological stability of the Crimea landscapes}

\section{V.O. Zhuk}

\begin{abstract}
The article analyzes the effects of dangerous hydrometeorological, affecting the sustainability of landscapes in the Crimea. The most stable landscape zones in the research area have been revealed. The stability of the Crimean landscapes to dangerous weather phenomena can serve as a basis for agronomy and agriculture, landscape planning, assessment of its ecological potential and permissible anthropogenic development of the area.
\end{abstract}

Key words: hazardous hydrometeorological phenomena, landscape, Crimean Peninsula.

\section{ВВЕДЕНИЕ}

Для оценки потенциальной гидрометеорологической устойчивости ландшафтов Крыма, анализировались нарушения природной среды, возникающие под воздействием опасных гидрометеорологических явлений. Привлечены архивные данные регулярных гидрометеорологических наблюдений Крымского управления по гидрометеорологии и мониторингу окружающей среды [16], были подсчитаны случаи проявления, а затем и проанализированы последствия проявления следующих опасных метеоявлений: выпадение града, ливневые дожди, сильные ветры со шквалом, пыльные бури, изморозь, ливневые снегопады и снежные метели. При анализе устойчивости ландшафтов к воздействию опасных гидрометеорологических явлений, мы также и опирались на региональные и локальные ландшафтно-географические закономерности [2, 15].

() Жук В.О., 2019

\section{МЕТОДИКА ЭКСПЕРИМЕНТА}

Информационной базой в процессе исследования были аналитическая и оперативная информация ФГБУ «Крымское управление по гидрометеорологии и мониторингу окружающей среды» [16]; отчетность и аналитическая информация Министерства аграрной политики Крыма [3]. Базовыми материалами для оценки метеорологических условий и анализа их влияния на процессы развития сельскохозяйственных культур служили научнометодическая и справочная агрометеорологическая литература $[3,4,6]$.

Во время проведения исследований использовали картографический, геоинформационный, системный, комплексный и сравнительный методы анализа информации, метод ландшафтного анализа и ландшафтно-экологические, агроэкологические и агрометеорологические научно-методические подходы, экономико-статистические и абстрактно-логические методы; использована ландшафтная карта Гришанкова [15], карты - проявления 
Ранжирование класса устойчивости ландшафтов Крыма

\begin{tabular}{|c|c|c|c|c|c|c|c|}
\hline 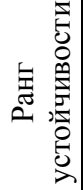 & $\begin{array}{c}\text { Степень } \\
\text { потенциальной } \\
\text { опасности } \\
\text { проявления } \\
\text { ОЯ }\end{array}$ & $\begin{array}{c}\text { Вероятность } \\
\text { градобития } \\
\text { в \% }\end{array}$ & $\begin{array}{c}\text { Опасность } \\
\text { подтопления } \\
\text { в м. }\end{array}$ & $\begin{array}{c}\text { Степень } \\
\text { потенциальной } \\
\text { опасности } \\
\text { проявления } \\
\text { пыльных бурь }\end{array}$ & $\begin{array}{c}\text { Степень } \\
\text { трансформ. } \\
\text { пашни } \\
\text { эрозией } \\
\text { в \% }\end{array}$ & $\begin{array}{c}\text { Актив. } \\
\text { оползней } \\
\text { м/год }\end{array}$ & $\begin{array}{c}\text { V/ед. выносов } \\
\text { селевого } \\
\text { материала }\end{array}$ \\
\hline 1 & Оч. высокая & $61-65$ & $0,6>$ & Низкая & $81-85$ & $1-2$ & $\begin{array}{l}100000- \\
1 \times 10^{6} \mathrm{~m}^{3}\end{array}$ \\
\hline 2 & Оч. высокая & $56-60$ & $0,6>$ & Средняя & $75-80$ & $0,5-0,8$ & $\begin{array}{c}20000- \\
100000 \mathrm{M}^{3}\end{array}$ \\
\hline 3 & Высокая & $51-55$ & 0,5 & Средняя & $70-74$ & $<0,5$ & $<20000 \mathrm{M}^{3}$ \\
\hline 4 & Высокая & $46-50$ & 0,5 & Высокая & $65-69$ & - & - \\
\hline 5 & $\begin{array}{c}\text { Относ. } \\
\text { невысокая }\end{array}$ & $41-45$ & 0,4 & Высокая & $60-64$ & - & - \\
\hline 6 & $\begin{array}{c}\text { Относ. } \\
\text { невысокая }\end{array}$ & $36-40$ & 0,4 & Средняя & $55-59$ & - & - \\
\hline 7 & Средняя & $31-35$ & 0,3 & Средняя & $50-54$ & - & - \\
\hline 8 & Средняя & $26-30$ & 0,3 & Оч. высокая & $45-49$ & - & - \\
\hline 9 & Низкая & $21-25$ & 0,2 & Оч. высокая & $40-44$ & - & - \\
\hline 10 & Низкая & $16-20$ & 0,2 & Высокая & $35-39$ & - & - \\
\hline 11 & Оч. низкая & $11-15$ & $<0,1$ & Оч. высокая & $60-64$ & - & - \\
\hline 12 & Оч. низкая & $5-10$ & $<0,1$ & Высокая & $75-80$ & - & - \\
\hline
\end{tabular}

опасных и стихийных гидрометеорологических явлений в Крыму [5, 6, 9], гидрологическая, геоморфологическая, климатическая информация, карта оползневой и селевой опасности Крыма $[2,3,8$, 11], а также ряд фундаментальных работ по данной тематике [4, 10, 13, 15].

\section{ОБСУЖДЕНИЕ РЕЗУЛЬТАТОВ}

По степени потенциальной гидрометеорологической устойчивости, ландшафты подразделяем на 12 группировок, которым присваиваются соответствующие значения устойчивости, ранжированные по двенадцати бальной шкале. Эти значения рассматриваются как исходный балл или фоновая устойчивость к воздействию опасных гидрометеорологических явлений, влияющих на возникновение неблагоприятных природных процессов [1]. К таким явлениям и процессам мы относим: градобитие, подтопление территории, водная и ветровая эрозия, пыльные бури, активизация селей, оползней и абразионных процессов. По силе интенсивности приведенных явлений и процессов, мы определяем степень устойчивости ландшафтов методом наложения построенных карт.

Градобитие. Ежегодно от градобития страдают сотни сельскохозяйственных предприятий Республики Крым. В 2017 году ущерб составил 38 млн. рублей, град повредил 410 га виноградников на южном берегу Крыма (ЮБК). В 2018 году потери были еще больше - около 55 млн. рублей, а площадь повреждений в северо-восточном Крыму составляла 395 га $[16,13]$. Сильный град был также отмечен в 2016, 2012, 2011 и 2010 годах. Сложность регистрации градобития заключается в том, что град - это узколокализованное, быстротекущее явление. Зачастую град выпадает на сельхозугодьях, а окружающие метеорологические станции его не отмечают. Однако, по статистическим данным ФГБУ «Крымского УГМС» [16] мы можем определить вероятность выпадения града над определенной территорией по количеству случаев выпадения града в году и дней с грозами на полуострове по формуле.

$$
\frac{100 \times X}{Y},
$$

где $X$ - это число дней в году с градом, $Y$ - число дней в году с грозой.

Так, в Симферополе (АМСГ Симферополь, 204 м) число случаев проявления града в году в среднем значении за пятилетие (2010-2015 гг.) 6 случаев, а число дней с грозой - 18, следовательно, вероятность выпадения града составляет $33 \%$.

Над большей частью равнинного Крыма вероятность выпадения града во время грозы составляет 10-15\%, в Предгорье в среднем 45-50\%, в Севастополе 50-55 \%, в горах 20-25\%, на ЮБК 25-30\%. 
Характеристика устойчивости ландшафтов Крыма

\begin{tabular}{|c|c|c|c|}
\hline & $\begin{array}{l}\text { ровень/зона } \\
\text { андшафтов }\end{array}$ & Пояс & $\begin{array}{c}\text { Преобладающая } \\
\text { степень } \\
\text { устойчивости }\end{array}$ \\
\hline $\begin{array}{l}\text { Гидрс } \\
\text { Низмс } \\
\text { недре }\end{array}$ & $\begin{array}{l}\text { орфный } \\
\text { ыые } \\
\text { рованные и }\end{array}$ & $\begin{array}{l}\text { 1. Прибрежных недренированных низменностей, } \\
\text { пляжей и кос с галофитными лугами, солончаками и } \\
\text { сообществами псаммофитов }\end{array}$ & $\begin{array}{c}\text { Наиболее } \\
\text { неустойчивые }\end{array}$ \\
\hline $\begin{array}{l}\text { слабо } \\
\text { аккум } \\
\text { и дену } \\
\text { типча }\end{array}$ & $\begin{array}{l}\text { ятированные } \\
\text { ятивные } \\
\text { ционные равнины с } \\
\text { во-ковыльными, }\end{array}$ & $\begin{array}{l}\text { 2. Аккумулятивных и денудационных } \\
\text { недренированных и слабодренированных } \\
\text { низменностей с полынно-типчаковыми, полынно- } \\
\text { житняковыми и ковыльно-типчаковыми степями }\end{array}$ & Неустойчивые \\
\hline $\begin{array}{l}\text { полын } \\
\text { полың } \\
\text { степя }\end{array}$ & $\begin{array}{l}\text {-типчаковыми, } \\
\text { р-житняковыми } \\
\text { в комплексе с }\end{array}$ & $\begin{array}{l}\text { 3. Аккумулятивных и денудационных } \\
\text { слабодренированных равнин с ковыльно- } \\
\text { типчаковыми и полынно-типчаковыми степями }\end{array}$ & $\begin{array}{l}\text { Относительно- } \\
\text { неустойчивые }\end{array}$ \\
\hline $\begin{array}{l}\text { галоф } \\
\text { степя }\end{array}$ & ными лугами и & $\begin{array}{l}\text { 4. Аккумулятивных дренированных и } \\
\text { слабодренированных низменностей с ковыльно- } \\
\text { типчаковыми степями в комплексе с ковыльно- } \\
\text { разнотравными степями }\end{array}$ & $\begin{array}{l}\text { Умеренно- } \\
\text { устойчивые }\end{array}$ \\
\hline $\begin{array}{l}\text { Плак } \\
\text { Типич }\end{array}$ & ный & $\begin{array}{l}\text { 5. Верхний денудационный ярус ковыльно- } \\
\text { типчаковых, петрофитных и кустарниковых степей }\end{array}$ & $\begin{array}{c}\text { Наиболее } \\
\text { устойчивые }\end{array}$ \\
\hline $\begin{array}{l}\text { типча } \\
\text { разно } \\
\text { типча } \\
\text { компЈ } \\
\text { и куст }\end{array}$ & $\begin{array}{l}\text { вые и бедно- } \\
\text { авно-ковыльно- } \\
\text { вые степи в } \\
\text { се с петрофитными } \\
\text { никовыми степями }\end{array}$ & $\begin{array}{l}\text { 6. Нижний денудационно-аккумулятивный ярус с } \\
\text { ковыльно-типчаковыми, кустарниково- } \\
\text { разнотравными и петрофитными степями }\end{array}$ & $\begin{array}{c}\text { Наиболее } \\
\text { устойчивые }\end{array}$ \\
\hline Низке & $\begin{array}{l}\text { рный } \\
\text { ные }\end{array}$ & $\begin{array}{l}\text { 7. Бородачево-разнотраных и асфоделиново- } \\
\text { разнотравных степей на аккумулятивных и } \\
\text { денудационных равнинах }\end{array}$ & $\begin{array}{l}\text { Относительно- } \\
\text { устойчивые }\end{array}$ \\
\hline $\begin{array}{l}\text { денум } \\
\text { струк } \\
\text { денуд } \\
\text { куэст }\end{array}$ & $\begin{array}{l}\text { ионные и } \\
\text { ионе } \\
\text { ионые равнины и } \\
\text { мозвышенности с }\end{array}$ & $\begin{array}{l}\text { 8. Лесостепи на останцово-денудационных, } \\
\text { структурных денудационных и аккумулятивных } \\
\text { равнинах, куэстовых возвышенностях }\end{array}$ & $\begin{array}{l}\text { Относительно- } \\
\text { неустойчивые }\end{array}$ \\
\hline $\begin{array}{l}\text { разно } \\
\text { куста } \\
\text { лесос } \\
\text { дубов }\end{array}$ & $\begin{array}{l}\text { авными степями, } \\
\text { иковыми зарослями, } \\
\text { Іью и низкорослыми } \\
\text { ии лесами }\end{array}$ & $\begin{array}{l}\text { 9. Дубовых лесов и кустарниковых зарослей на } \\
\text { останцово-денудационных и наклонных структурных } \\
\text { денудационных равнинах и куэстовых } \\
\text { возвышенностях }\end{array}$ & $\begin{array}{l}\text { Относительно- } \\
\text { устойчивые }\end{array}$ \\
\hline & $\begin{array}{l}\text { Северный макро- } \\
\text { склон гор, буковые, }\end{array}$ & $\begin{array}{l}\text { 10. Котловин и эрозионного низкогорья, дубовых, } \\
\text { смешанных широколиственных и сосновых лесов }\end{array}$ & $\begin{array}{c}\text { Наиболее } \\
\text { неустойчивые }\end{array}$ \\
\hline & & $\begin{array}{l}\text { 11. Среднегорно-склоновый, дубовых, можжевелово- } \\
\text { дубовых и смешанных широколиственных лесов }\end{array}$ & Неустойчивые \\
\hline & $\begin{array}{l}\text { широколиственные } \\
\text { леса }\end{array}$ & $\begin{array}{l}\text { 12. Среднегорно-склоновый, буковых, буково- } \\
\text { грабовых, смешанных широколиственных лесов }\end{array}$ & Неустойчивые \\
\hline 3 & Яйлинские плато, & 13. Лесных и лугово-лесостепных плато & $\begin{array}{l}\text { Относительно- } \\
\text { устойчивые }\end{array}$ \\
\hline$\stackrel{\widetilde{2}}{\stackrel{2}{2}}$ & $\begin{array}{l}\text { горные луга и } \\
\text { горная лесостепь }\end{array}$ & 14. Луговых и лугово-лесных плато & $\begin{array}{l}\text { Относительно- } \\
\text { устойчивые }\end{array}$ \\
\hline కั & Южный & $\begin{array}{l}\text { 15. Низкогорно-склоновый дубовых и смешанных } \\
\text { широколиственных лесов }\end{array}$ & Неустойчивые \\
\hline & дубовые, сосновые & $\begin{array}{l}\text { 16. Среднегорно-склоновый, дубовых, сосновых и } \\
\text { смешанных широколиственных лесов }\end{array}$ & Неустойчивые \\
\hline & леса & 17. Буковых и смешанных широколиственных лесов & Неустойчивые \\
\hline 疍 & $\begin{array}{l}\text { Южный } \\
\text { макросклон гор, } \\
\text { полусубтропичес- }\end{array}$ & $\begin{array}{l}\text { 18. Дубово-фисташковых, можжевелово-сосновых } \\
\text { лесов и шибляковых зарослей }\end{array}$ & $\begin{array}{c}\text { Наиболее } \\
\text { неустойчивые }\end{array}$ \\
\hline 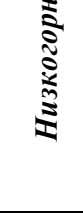 & $\begin{array}{l}\text { фисташково- } \\
\text { дубовые, } \\
\text { можжевелово- } \\
\text { сосновые леса и } \\
\text { шибляковые } \\
\text { заросли }\end{array}$ & $\begin{array}{l}\text { 19. Сосновых, дубовых и смешанных } \\
\text { широколиственных лесов и шибляковых зарослей }\end{array}$ & Неустойчивые \\
\hline
\end{tabular}


Наиболее потенциально-опасная зона для выпадения града - Предгорье Крыма (Белогорск, Бахчисарай - до $65 \%$ гроз с выпадением града). В большинстве случаев увеличению повторяемости выпадения града здесь способствует развитие восходящих токов перед горами, усиление турбулентности в приземном слое воздуха и, как следствие, увеличение конвективной облачности. Значительно реже выпадает град в северо-западных районах Крыма и прибрежной полосе ЮБК вследствие влияния бризовой циркуляции [10, 13].

Подтопление территории. Наибольшая потенциальная опасность подтопления территории и возникновения наводнений в Крыму, после прохождения сильных ливней, отмечается в Предгорном Крыму и на ЮБК (в Симферополе, Белогорске, Севастополе, Бахчисарае, Феодосии, Судаке, Ялте, Алуште). Здесь во время интенсивных осадков воду спускают одновременно из нескольких водохранилищ, что приводит к наводнениям. В частности, это отмечается и в бассейнах рек, когда во время значительных паводков происходит затопление сельхозугодий и населенных пунктов $[11,12]$.

Пыльные бури и водная эрозия почв. Наиболее интенсивно ветровая эрозия протекает в Раздольненском, Сакском, Красногвардейском и Черноморском районах [6]. При выдувании 1 см почвы общие потери плодородной земли в Крыму составляют 143 млн. т. Среднегодовые потери от ветровой и водной эрозии составляют 11 млн. т гумуса. В степных районах в среднем за год может сдуваться 22,7 т почвы с гектара, что со всей площади пашни составляет более 2 млн. т $[4,6]$. Исключительно сильные и продолжительные пыльные бури чаще всего наблюдались в зимнее и весеннее время года в Раздольненском, Черноморском, Сакском, Кировском районах, где снос почвы может достигать до 10-12 см.

Проявление опасных гидрометеорологических явлений. Высокая степень проявления опасных гидрометеорологических явлений отмечается на границе степного и предгорного Крыма, в Предгорье - в Симферопольском районе (> 40 случаев ОЯ за период 2010-2015 гг.) и Горном Крыму - в Белогорском и Бахчисарайском районах (от 30 до 40 случаев). На юго-восточном побережье Крыма (г. Алушта - 20 случаев). В Ленинском и Кировском районах отмечается от 15 до 20 случаев за пятилетие. Наименьшее проявление ОЯ в районах Красноперекопском, Раздольненском, Севастопольский городской совет, в Феодосийском и Ар- мянском городских советах (<10 случаев ОЯ за пятилетие) Наиболее наблюдаемыми ОЯ на полуострове являются ливневые дожди и сильные ветры со шквалом [5, 8, 9].

Степень потенциальной гидрометеорологической устойчивости ландиафтов. Степень потенциальной гидрометеорологической устойчивости относится к определенному рангу, показывающему к какой категории относится та или иная область. За ранг 1 принимается минимальное значение (наиболее неустойчивый ландшафт), следовательно, чем выше ранг, тем степень устойчивости будет увеличиваться [1, 6, 7]. И максимального своего значения она достигнет в ранге 12 (наиболее устойчивый ландшафт). Методика ранжирования представлена в таблице 1 .

Устойчивость ландшафтов в рангах: 1-2 - наиболее неустойчивые, 3-4 - неустойчивые, 5-6 - относительно-неустойчивые, 7-8 - относительно-устойчивые, 9-10 - устойчивые, 11-12 - наиболее устойчивые.

Компактно распределение устойчивости ландшафтов Крымского полуострова характеризуется в таблице 2 .

\section{ЗАКЛЮЧЕНИЕ}

Наиболее неустойчивые ландшафты отмечены на Западном побережье Равнинного Крыма (Сакский, Черноморский районы), на границе степного и предгорного Крыма (Симферопольский, Бахчисарайский, Белогорский районы), а также в зонах Северного и Южного макросклонов Крымских гор и на ЮБК. В центральных районах - наиболее устойчивые (Первомайский, Красногвардейский, Джанкойский районы). В целом, в Равнинном Крыму, преобладают наиболее устойчивые ландшафты, в Предгорном - наиболее неустойчивые, в Горном Крыму и на ЮБК - неустойчивые.

Исследование выполнено при поддержке РФФИ и Совета Министров Республики Крым в рамках научного проекта № 17-45-92015.

\section{СПИСОК ЛИТЕРАТУРЫ}

1. Абалаков А. Д. Устойчивость ландшафтов и ее картографирование / А. Д. Абалаков, Д. А. Лопаткин // Известия Иркутского государственного университета. Сер. Науки о Земле. - 2014. - № 8 - С. 2-14.

2. Автономная Республика Крым : атлас / Н. В. Багров [и др.]. - Киев-Симферополь, 2003. - 80 с.

3. Ведь И. П. Климатический атлас Крыма. Симферополь / И. П. Ведь. - Симферополь : Таврия-Плюс, 2000. - $120 \mathrm{c}$.

4. Ергина Е. И. Пространственно-временные закономерности процессов современного почвообразования 
на Крымском полуострове / Е. И. Ергина. - Симферополь : АРИАЛ, 2017. - 224 с.

5. Ергина Е. И. Анализ проявления опасных и стихийных гидрометеорологических явлений в Крыму / Е. И. Ергина, В. О. Жук // Окружающая среда и человек. - Ростов-на-Дону : ЮНЦ РАН, 2016. - С. 85-88.

6. Ергина Е. И. Влияние современных тенденций климата на состояние эрозионноопасных агроландшафтов и оценка почвообразующего потенциала природных факторов Крыма / Е. И. Ергина, В. О. Жук // Известия Оренбургского государственного аграрного университета. - 2017. - № 3. - С. 175-178.

7. Ергина Е. И. О росте опасных и стихийных гидрометеорологических явлений на Крымском полуострове / Е. И. Ергина, В. О. Жук // Известия высших учебных заведений. Северо-Кавказский регион. Сер. Естественные науки. - 2018. - №1. - С. 68-74.

8. Жарковский К. Ю. Оползни Крыма : курсовая работа / К. Ю. Жарковский. - Симферополь, 2011. - 42 с. - URL : http://stud.wiki/geology/2c0a65625b3ad78a4d53a 88421216d37_0.html (дата обращения 18.10.18 г.).

9. Жук В. О. Проявление опасных и стихийных гидрометеорологических явлений в ландшафтах Крыма / В. О. Жук, Е. И. Ергина // Ландшафтная география в XXI веке : материалы Международной научной конференции / под ред. Е. А. Позаченюк. - Симферополь, 2018. - С. 270-273.

10. Логвинова К. Т. Климат и опасные гидрометеорологические явления Крыма / К. Т. Логвинова, М. Б. Барабаш. - Ленинград : Гидрометеоиздат, 1982. 317 c.

11. Олиферов А. Н. Реки и озера Крыма / А. Н. Олиферов, 3. В. Тимченко. - Симферополь : Доля, 2005. $216 \mathrm{c}$.

12. Олиферов А. Н. Экогеодинамика водных ресурсов Крыма / А. Н. Олиферов, 3. В. Тимченко // Геополитика и экогеодинамика регионов. - 2005. - № 1. C. $115-125$.

13. Паштецкий В. С. Влияние неблагоприятных природных явлений на деградацию почв и агропромышленный комплекс Крыма / В. С. Паштецкий, К. Г. Женченко, А. В. Приходько // Бюллетень Почвенного института им. В. В. Докучаева. - 2015. - № 77. - С. 94-105.

14. Преображенский В. С. Проблема изучения устойчивости геосистем / В. С. Преображенский // Устойчивость геосистем. - Москва : Недра, 1983. - С. 4-7.

15. Современные ландшафты Крыма и сопредельных акваторий / под ред. Е. А. Позаченюк. - Симферополь : Бизнес-Информ, 2009. - 672 с.

16. Статистика проявления опасных и стихийных гидрометеорологических явлений в Крыму : архивные данные Федерального государственного бюджетного учреждения «Крымское управление по гидрометеорологии и мониторингу окружающей среды» // Государственный Архив Республики Крым. - Симферополь, 2015.

\section{REFERENCES}

1. Abalakov A. D. Ustoychivost' landshaftov i ee kartografirovanie / A. D. Abalakov, D. A. Lopatkin // Izvestiya Irkutskogo gosudarstvennogo universiteta. Ser. Nauki o Zemle. - 2014. - № 8 - S. 2-14.

2. Avtonomnaya Respublika Krym : atlas / N. V. Bagrov [i dr.]. - Kiev-Simferopol', 2003. - $80 \mathrm{~s}$.

3. Ved' I. P. Klimaticheskiy atlas Kryma. Simferopol' / I. P. Ved'. - Simferopol' : Tavriya-Plyus, 2000. - 120 s.

4. Ergina E. I. Prostranstvenno-vremennye zakonomernosti protsessov sovremennogo pochvoobrazovaniya na Krymskom poluostrove/ E. I. Ergina. - Simferopol' : ARIAL, 2017. - 224 s.

5. Ergina E. I. Analiz proyavleniya opasnykh i stikhiynykh gidrometeorologicheskikh yavleniy v Krymu / E. I. Ergina, V. O. Zhuk// Okruzhayushchaya sreda i chelovek. - Rostov-na-Donu : YuNTs RAN, 2016. - S. 85-88.

6. Ergina E. I. Vliyanie sovremennykh tendentsiy klimata na sostoyanie erozionnoopasnykh agrolandshaftov i otsenka pochvoobrazuyushchego potentsiala prirodnykh faktorov Kryma / E. I. Ergina, V. O. Zhuk // Izvestiya Orenburgskogo gosudarstvennogo agrarnogo universiteta. 2017. - № 3. - S. 175-178.

7. Ergina E. I. O roste opasnykh i stikhiynykh gidrometeorologicheskikh yavleniy na Krymskom poluostrove / E. I. Ergina, V. O. Zhuk // Izvestiya vysshikh uchebnykh zavedeniy. Severo-Kavkazskiy region. Ser. Estestvennye nauki. - 2018. - №1. - S. 68-74.

8. Zharkovskiy K. Yu. Opolzni Kryma : kursovaya rabota / K. Yu. Zharkovskiy. - Simferopol', 2011. - 42 s. URL : http://stud.wiki/geology/2c0a65625b3ad78a4d53a 88421216d37_0.html (data obrashcheniya 18.10.18 g.).

9. Zhuk V. O. Proyavlenie opasnykh i stikhiynykh gidrometeorologicheskikh yavleniy v landshaftakh Kryma / V. O. Zhuk, E. I. Ergina // Landshaftnaya geografiya v XXI veke : materialy Mezhdunarodnoy nauchnoy konferentsii / pod red. E. A. Pozachenyuk. - Simferopol', 2018. S. 270-273.

10. Logvinova K. T. Klimat i opasnye gidrometeorologicheskie yavleniya Kryma / K. T. Logvinova, M. B. Barabash. - Leningrad : Gidrometeoizdat, 1982. - 317 s.

11. Oliferov A. N. Reki i ozera Kryma / A. N. Oliferov, Z. V. Timchenko. - Simferopol' : Dolya, 2005. - 216 s.

12. Oliferov A. N. Ekogeodinamika vodnykh resursov Kryma / A. N. Oliferov, Z. V. Timchenko // Geopolitika i ekogeodinamika regionov. - 2005. - № 1. - S. 115-125.

13. Pashtetskiy V. S. Vliyanie neblagopriyatnykh prirodnykh yavleniy na degradatsiyu pochv i agropromyshlennyy kompleks Kryma / V. S. Pashtetskiy, K. G. Zhenchenko, A. V. Prikhod'ko// Byulleten' Pochvennogo instituta im. V. V. Dokuchaeva. - 2015. - № 77. S. 94-105.

14. Preobrazhenskiy B. C. Problema izucheniya ustoychivosti geosistem / B. C. Preobrazhenskiy // Ustoychivost' geosistem. - Moskva : Nedra, 1983. - S. 4-7. 
15. Sovremennye landshafty Kryma i sopredel'nykh akvatoriy / pod red. E. A. Pozachenyuk. - Simferopol' : Biznes-Inform, 2009. - $672 \mathrm{~s}$.

16. Statistika proyavleniya opasnykh i stikhiynykh gidrometeorologicheskikh yavleniy v Krymu : arkhivnye dan-

Жук Владимир Олегович

аспирант географического факультета Таврической академии Крымского федерального университета им. В.И. Вернадского, г. Симферополь, Республика Крым, E-mail: Zhuk vladimir2015@mail.ru nye Federal'nogo gosudarstvennogo byudzhetnogo uchrezhdeniya «Krymskoe upravlenie po gidrometeorologii i monitoringu okruzhayushchey sredy» // Gosudarstvennyy Arkhiv Respubliki Krym. - Simferopol', 2015.

Zhuk Vladimir Olegovich

Postgraduate student of the Geography Faculty of the Tavricheskaya Academy of the Crimean Federal University named after V.I. Vernadsky, Simferopol, Republic of Crimea, E-mail: Zhuk vladimir2015@mail.ru 